\title{
Application of atomic force microscopy in cancer research
}

\author{
Xiangying Deng ${ }^{1,2,3}$, Fang Xiong ${ }^{2}$, Xiayu Li ${ }^{2,3}$, Bo Xiang ${ }^{1,2,3}$, Zheng $\mathrm{Li}^{1,2,3}, \mathrm{Xu} \mathrm{Wu}^{2,4}$, Can Guo ${ }^{2}$, Xiaoling Li $\mathrm{i}^{1,2,3}$, \\ Yong $\mathrm{Li}^{2,5}$, Guiyuan $\mathrm{Li}^{1,2,3}$, Wei Xiong ${ }^{1,2,3^{*}}$ and Zhaoyang Zeng ${ }^{1,2,3^{*}}$
}

\begin{abstract}
Atomic force microscopy (AFM) allows for nanometer-scale investigation of cells and molecules. Recent advances have enabled its application in cancer research and diagnosis. The physicochemical properties of live cells undergo changes when their physiological conditions are altered. These physicochemical properties can therefore reflect complex physiological processes occurring in cells. When cells are in the process of carcinogenesis and stimulated by external stimuli, their morphology, elasticity, and adhesion properties may change. AFM can perform surface imaging and ultrastructural observation of live cells with atomic resolution under near-physiological conditions, collecting force spectroscopy information which allows for the study of the mechanical properties of cells. For this reason, AFM has potential to be used as a tool for high resolution research into the ultrastructure and mechanical properties of tumor cells. This review describes the working principle, working mode, and technical points of atomic force microscopy, and reviews the applications and prospects of atomic force microscopy in cancer research.
\end{abstract}

Keywords: Atomic force microscopy, Cancer cells, Morphology, Mechanical properties

\section{Background}

As unconstrained and rapidly dividing cells, the physicochemical properties of cancer cells have changed in comparison with the normal cells from which they are derived [1]. During the invasion and metastasis of cancer cells, the adhesion between cells is reduced, and the shape and hardness of the cells changes according to the surrounding environment [2-4], in order to meet the physiological activities of cancer cells themselves. Therefore, researchers can determine whether or not cells are cancerous, whether the cancer cells are invasive or metastasize, and the effects of drugs on cancer cells and so on by the physical properties such as hardness, adhesion, and Young's modulus. However, in order to achieve the above research, it is necessary to observe and manipulate cells at a nanometer level of resolution. Atomic force microscopy (AFM) is an extremely high resolution

\footnotetext{
*Correspondence: xiongwei@csu.edu.cn; zengzhaoyang@csu.edu.cn ${ }^{1}$ The Key Laboratory of Carcinogenesis of the Chinese Ministry of Health and Hunan Key Laboratory of Translational Radiation Oncology, Hunan Cancer Hospital and The Affiliated Cancer Hospital of Xiangya School of Medicine, Central South University, Changsha 410013, Hunan, China Full list of author information is available at the end of the article
}

tool, which can be used to observe the morphology of a sample, and quantitatively measure its mechanical properties at atomic resolution. For this reason, AFM has applications in cancer research. The technique was invented in 1986 by IBM's G. Binnig, and C. F. Quate and C. Gerber at Stanford University [5]. AFM is the highestresolution and most widely used member of the scanning force microscopy (SFM) family, with a horizontal resolution of $0.1 \mathrm{~nm}$, a vertical resolution of $0.01 \mathrm{~nm}$, and an atomic level of resolution. It goes beyond the limits of the resolution of microscopes which use light and electron wavelengths. AFM uses a microscopic physical probe to "grope" the microcosm and observes the morphology of the sample under investigation in three-dimensional space, obtaining information from the very weak interaction between the probe and the sample surface.

The technical advantages of AFM are the main reasons for its rapid and widespread adoption in biology and medicine [6]. Firstly, due to the extremely high resolution of AFM, it is possible to perform direct three-dimensional imaging of molecular, and even atomic-scale structures. Secondly, sample preparation for AFM is straightforward, the damage to the original 
structure is small, and the original appearance of the sample can be determined objectively and accurately. Thirdly, due to the fact that samples can be observed under near-physiological conditions, the dynamic processes of molecules, organelles, and other structures in living cells can be recorded in real time by AFM [7]. Fourthly, AFM can measure intermolecular forces, charge, $\mathrm{pH}$, and other physicochemical characteristics of sample materials. Finally, the functionalized probe can be used to identify specific molecules or interaction forces such as ligand-receptor interactions. Therefore, AFM has good prospects for application in biomedicine and clinical medicine, and particularly in the diagnosis and treatment of cancer. Cell mechanics is a promising biomarker for indicating cell states [813]. The mechanics of cells can be measured by many methods including, among others, magnetic twisting cytometry, optical tweezers, and atomic force microscopy. Of these methods, however, AFM is the most widely used tool for this purpose [14-16]. The advantages and disadvantages of these methods are summarized in Table 1.

At present, the study of the physical properties of tumors is not sufficiently thorough. In view of the various unique advantages of AFM, it may be used to investigate changes in ultrastructure and mechanical properties within tumor tissues and cells which, in turn, can be used as a basis for clinical adjuvant diagnosis [17]. At the same time, AFM allows for the exploration of the mechanisms of antitumor drugs at the cellular and molecular level; this allows for the evaluation of drug efficacy, and opens avenues for the prevention of tumor cell proliferation [18-22].

\section{The basic principle of AFM}

The AFM system consists of the following components: a micro-cantilever with probe, a micro-cantilever motion detection device, a feedback loop for monitoring micro-cantilever motion, a piezoelectric ceramic scanning device for sample scanning, and a computer-controlled image acquisition, display, and processing system (Fig. 1). AFM studies the surface structure and properties of the sample by detecting very weak interatomic interactions between the sample surface and the probe tip. The working principle is to fix one end of micro cantilever, which is extremely sensitive to weak force, while other end of cantilever contained in the probe brought into close proximity with the sample [23]. Once this has been accomplished, a very weak force, which may be either repulsive or attractive, exists between the tip atom of the probe and the atoms of the sample surface. The magnitude of this force changes the deformation of the micro cantilever or its motion state. When the sample is scanned, sensors are used to detect these changes and force distribution information is obtained, allowing the user to obtain surface structure information with nanometer resolution. The AFM scanner can move in the $\mathrm{X}, \mathrm{Y}$, and $\mathrm{Z}$ directions. While the distance traveled in the $\mathrm{X}$ and $\mathrm{Y}$ directions varies with the scanner, the vertical $\mathrm{Z}$ direction is typically limited to a few microns. At the same time, the morphology of the scanning area sample can be obtained by reconstructing the position of the piezoelectric ceramic scanning tube in the Z-direction and the $\mathrm{X}-\mathrm{Y}$ plane. The Young's modulus value of samples, like cells and tissues, is fitted with a linear fit by Hertz model, with a smaller Young's modulus indicating that the sample is more susceptible to deformation. The force-distance curve measured by AFM reflects the

Table 1 Comparison of representative methods in measuring cell mechanics $[8,14-16]$

\begin{tabular}{|c|c|c|}
\hline Methods & Advantages & Disadvantages \\
\hline Microfluidics & $\begin{array}{l}\text { High throughput ( } 1 \text { cell/s); ability to control cell environ- } \\
\text { ment and approximate physiological conditions }\end{array}$ & $\begin{array}{l}\text { Be prone to cell adhesion and clogging; limited materials } \\
\text { for fabricating devices; cell size is often neglected }\end{array}$ \\
\hline Micropipette aspiration & $\begin{array}{l}\text { Simple and cost-effective; large range of force (up } \\
\text { to } 100 \mathrm{nN} \text { ) }\end{array}$ & $\begin{array}{l}\text { Low throughput; limited special resolution (<1 cell/10 min); } \\
\text { possible damage to cells; mainly for suspended cells }\end{array}$ \\
\hline Micropost arrays & $\begin{array}{l}\text { Ability to measure the traction forces of single cells or cell } \\
\text { populations }\end{array}$ & $\begin{array}{l}\text { Mainly for adherent cells; high cost and complexity; the } \\
\text { topology of micropost arrays may influence cell activities }\end{array}$ \\
\hline Magnetic twisting cytometry & $\begin{array}{l}\text { Probing the local mechanics of cells; magnetic beads can } \\
\text { be bound with diverse types of cellular molecules or } \\
\text { structures }\end{array}$ & $\begin{array}{l}\text { Low throughput (<1 cell/min); difficult to standardize; only } \\
\text { for unidirectional forces }\end{array}$ \\
\hline Optical tweezers & $\begin{array}{l}\text { High precision measurements of small forces }\left(0.01-10^{3}\right. \\
\text { pN); can be integrated with microfluidic delivery }\end{array}$ & $\begin{array}{l}\text { Limited force }(<500 \mathrm{pN}) \text { applied on cells; detrimental effects } \\
\text { on cells due to heating }\end{array}$ \\
\hline Parallel plate & $\begin{array}{l}\text { Simple and cost-effective; ability to study single cells of } \\
\text { cell populations }\end{array}$ & Low throughout; low spatial resolution \\
\hline Atomic force microscopy & $\begin{array}{l}\text { Applicable for both suspended cells and adherent cells; } \\
\text { simultaneously obtain structural and mechanical infor- } \\
\text { mation with nanometer resolution }\end{array}$ & $\begin{array}{l}\text { Low throughput (<1 cell/10 min); the mechanical poking of } \\
\text { the AFM tip may influence cell activities }\end{array}$ \\
\hline
\end{tabular}




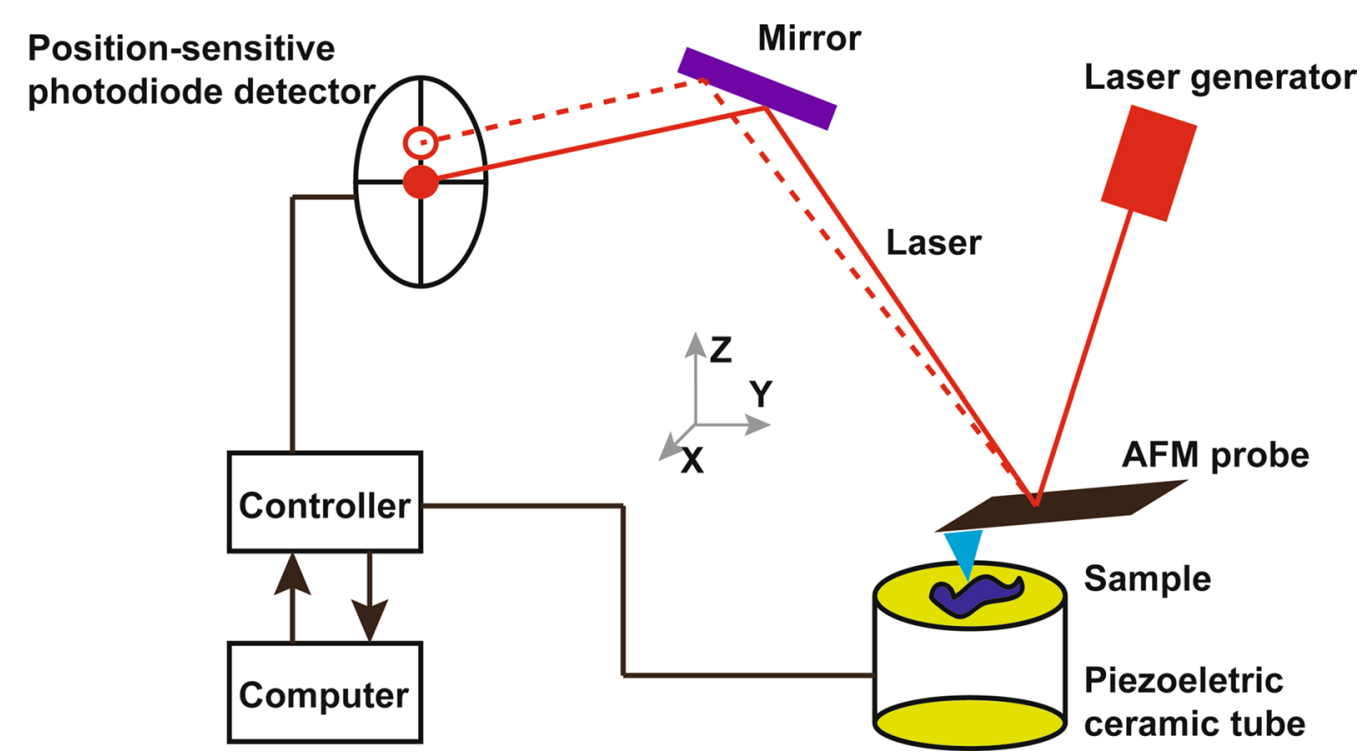

Fig. 1 Schematic diagram of AFM working principles. The AFM instrument is composed of a piezoelectric ceramic tube, a laser generator, a position-sensitive photodiode detector, a controller, and an AFM probe. The AFM probe is a micro-cantilever with a sharp tip attached at its end. The tip, which has a monomolecular point, allows for nanometer resolution imaging and the micro-cantilever is a force sensor that can detect even minute deformation of a sample, enabling very high sensitivity AFM in force measurements

quantitative force between the tip and the sample. Using the corresponding probes, equipped with dedicated software, AFM can measure the nano-indentation of the micro regions, and force-displacement curves drawn on this basis [24] can be used for the quantitative measurement of a material's elastic modulus, adhesion, and stiffness (Fig. 2) [25]. Each force curve is saved during the test for later quantitative analysis.

The principle of AFM imaging and mechanical property detection is based on the attraction and repulsive forces between atoms. The atoms at the tip of the probe and those on the surface of the sample are subjected to an attractive force when too far apart, and to a repulsive force when they are in close proximity (Fig. 3a). The basic imaging modes of AFM include: contact mode (Fig. 3b), non-contact mode (Fig. 3c), and tapping or semi-contact mode (Fig. 3d). In contact mode, the probe of AFM keeps a slight contact with the sample surface and maintains a constant force. In non-contact mode, the surface topography of the sample is produced by measuring the atomic attraction between the probe and the sample. In the tapping mode, the micro-cantilever of the probe is forced to move near the resonance frequency, and the probe makes contact with the sample intermittently. The force between the probes and sample can be kept constant by controlling the amplitude or deflection of the microcantilever when the probe touches the sample. Tapping mode effectively eliminates the influence of the lateral force and reduces the force caused by the adsorption layer, resulting in a high image resolution, especially for surface ultrastructure observation of biological samples.

The study of single cancer cells using AFM is expected to be advantageous in two aspects. On the one hand, the diagnosis of early cancer focuses on the observation of changes and differences between single cells, with the differences between cancerous and non-cancerous cells allowing for early diagnosis and treatment of cancer [26]. On the other hand, it allows for the study of the structure and function of cancer cells, the mechanisms involved in their spreading, interaction processes between cells, and the mechanisms of anti-cancer drugs, etc. The resultant findings from such studies should aid researchers in their goals of finding means of blocking cancer cell proliferation, and developing anti-cancer drugs [27-30].

\section{Observation of cancer cells morphology}

Using visible light microscopy, no significant differences in the surface morphology of white blood cells could be detected in cells from chronic leukemia patients and healthy subjects. However, observations of both cells under AFM revealed that a large number of needle-like structures appeared on the surface of leukocytes in leukemia patients, and that cell surface roughness was also significantly higher than that of normal white blood cells [31]. This indicated that the resolution of the AFM is significantly higher than that of the optical microscope, and is capable of distinguishing between differences in the ultrastructure of the cells. In addition to observations of 


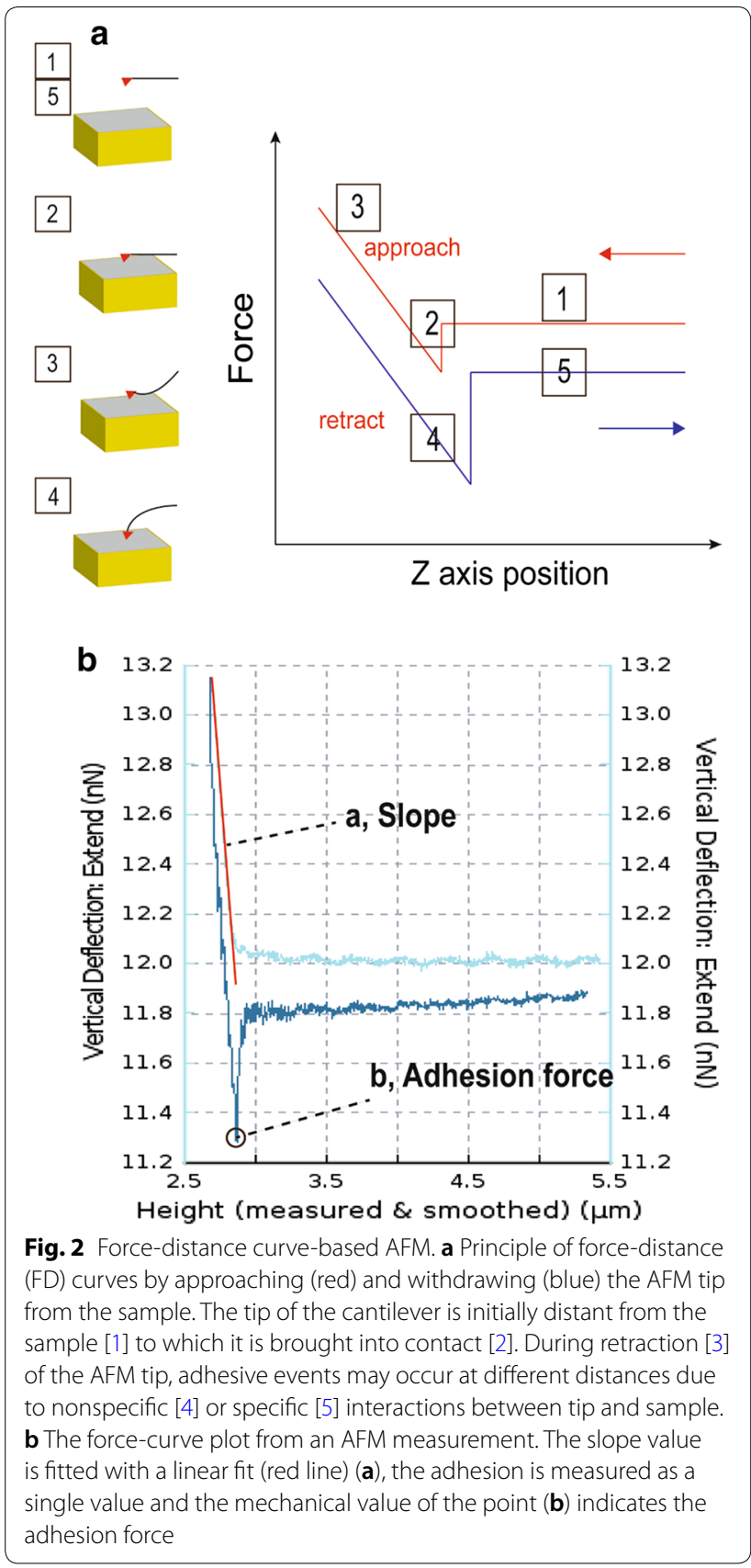

tumor cell lines, AFM can also scan patient's tumor tissue or cells for imaging. Hanekar et al. explored the relationship between SMAR1 expression and cell surface roughness under AFM in different grades of human breast cancer tissues [32]. This study illustrates that it is possible to observe the ultrastructure of the membrane surface of different types of tumor, and to analyze their common characteristics and differences. AFM can also highlight the significant differences in cell membrane morphology between normal cells and tumor cells, and can determine whether the cells are malignant or not, compared with tumor cells from the same source. This provides a reliable auxiliary basis for clinical pathological and differential diagnoses.

In cancer cells, the expression of certain genes may be either up-or down-regulated. For example, the CDX2 gene is less active in most patients with colorectal cancer $[33,34]$. Overexpression of CDX2 can inhibit the metastasis of this cancer, while further inhibiting its expression promotes metastasis $[35,36]$. It has been shown that CDX2 has tumor suppressing activity [37-39]. AFM detection showed that the stiffness of colon cancer cells increased with higher expression of CDX2, and that cell variability decreased, which weakened the ability of the cells to transfer to the extracellular matrix and capillaries [40]. Vascular endothelial growth factor D (VEGF-D) and vascular endothelial growth factor C (VEGF-C) are thought to be involved in the formation of lymphatic vessels and blood vessels [41, 42]. After transfecting a recombinant plasmid containing VEGF-D into lung cancer cells, AFM detection showed that irregular microspikes and nanoclusters appeared on the cell surfaces, and that cells became more rigid. Using AFM to observe the surface morphology of lung cancer cell PC9, the morphology image of cancer cells with high resolution could be obtained (Fig. $4 \mathrm{a}-\mathrm{c}$ ). The above studies demonstrate that AFM can be used to detect changes in the morphology of cancer cells caused by cancer-associated genes, providing an additional detection method for phenotypic changes which is complementary to traditional investigative methods.

\section{Mechanical properties of cancer cells}

The mechanical strength of cells plays an important role in the homeostasis of tissues, cell growth, division, migration, and epithelial-mesenchymal transition [43]. Numerous studies have shown that differences exist in the stiffness of normal and cancerous cells, and between primary and metastatic cancer cells. Cross et al. detected the cells of patients with suspected metastatic adenocarcinoma (lung, breast, and pancreatic cancer) using AFM. Studies have indicated that, even if benign and malignant cells are similar in shape and therefore difficult to distinguish by visual inspection, they may still be identified by mechanical analysis $[44,45]$. In addition, the Cross group also reported biomechanical differences between human mesothelial tumor cells and normal cells [46]. Other researchers have found that human bladder cancer cells have lower hardness than normal epithelial cells [47], and that human breast cancer MCF-7 cells are softer than MCF-10 cells [48]. These studies showed that it is possible to distinguish between cancer cells and normal cells, and between original and metastatic cancer cells, 


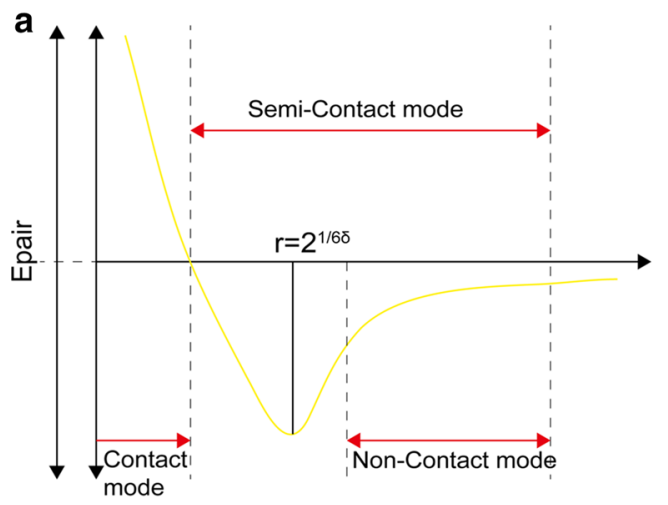

C

Non-Contact mode

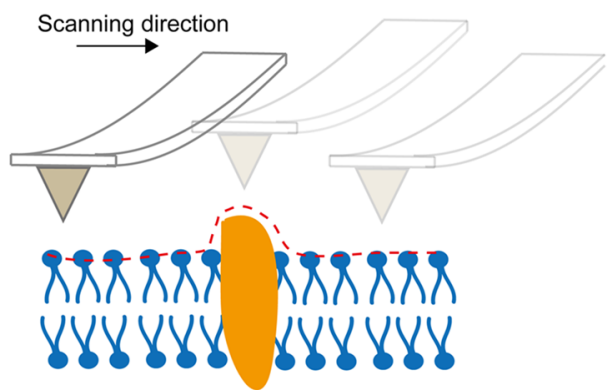

b

\section{Contact mode}

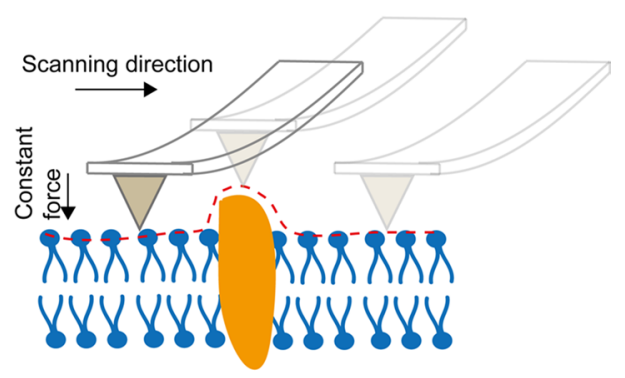

d

Semi-Contact mode

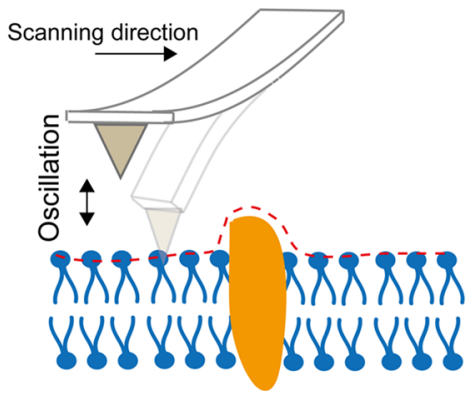

Fig. 3 Three basic working modes of AFM. a The curve of both interatomic force and intervals relation. $\mathbf{b}$ In contact mode the probe is always slightly contact with the sample and scanned in a constant force mode. $\mathbf{c}$ In the non-contact mode the tip of the needle always vibrates on the surface of the sample, but it is never contact with the sample. The scanning detector detects long-range forces such as van der Waals force or electrostatic forces that do not damage the imaged sample. $\mathbf{d}$ In the tapping mode the micro cantilever is subjected to stress vibration near its resonant frequency, and the oscillating needle tip gently strikes the surface of the sample, intermittently making contact with it

by detecting their mechanical properties using AFM. This provides a novel auxiliary means of clinical cancer diagnosis. The mechanical properties of lung cancer cell PC-9, including Young's modulus, adhesion, and stiffness, have also been quantitatively measured by AFM (Fig. 4d-f). This showed that AFM can not only detect the morphology of cancer cells, but also perform deeper mechanical properties and cell structure analysis on cancer cells.

The invasion and metastasis of tumor cells has an important relationship with the microenvironment. AFM measurement of extracellular matrix (ECM) micromechanics provides important insights into disease-induced tissue stiffness alterations [49]. It was found that normal liver tissue, liver fibrosis tissue, and liver cirrhosis were significantly different in terms of hardness when examined by AFM. There was no significant difference in hardness between liver cirrhosis tissue and hepatocellular carcinoma tissue [50]. This suggested that the hardness of the liver is increased during carcinogenesis, which may progress to liver cancer after cirrhosis. In addition, a series of studies have shown that cancer cells are more rigid than normal cells [51]. These findings disprove the idea that cancer cells tend to be softer than normal cells, and indicate that hardness depends on the needs of the cancer cells themselves during the process of carcinogenesis.

\section{The study of tumor-associated molecules and subcellular structures}

Circulating cell-free DNA (ccfDNA) is an important biomarker for the diagnosis and treatment of cancer [52], and can be indicative of changes in the genotype and phenotype of primary tumors [53]. It has been found that more than $80 \%$ of the ccfDNA fragments in the plasma of cancer patients are under $145 \mathrm{bp}$ in size, and that their size is always less than 300 bp [54]. Reduced fragmentation of ccfDNA is associated with increased overall survival. After chemotherapy, plasma ccfDNA fragmentation in normal patients is greatly reduced, while patients with 


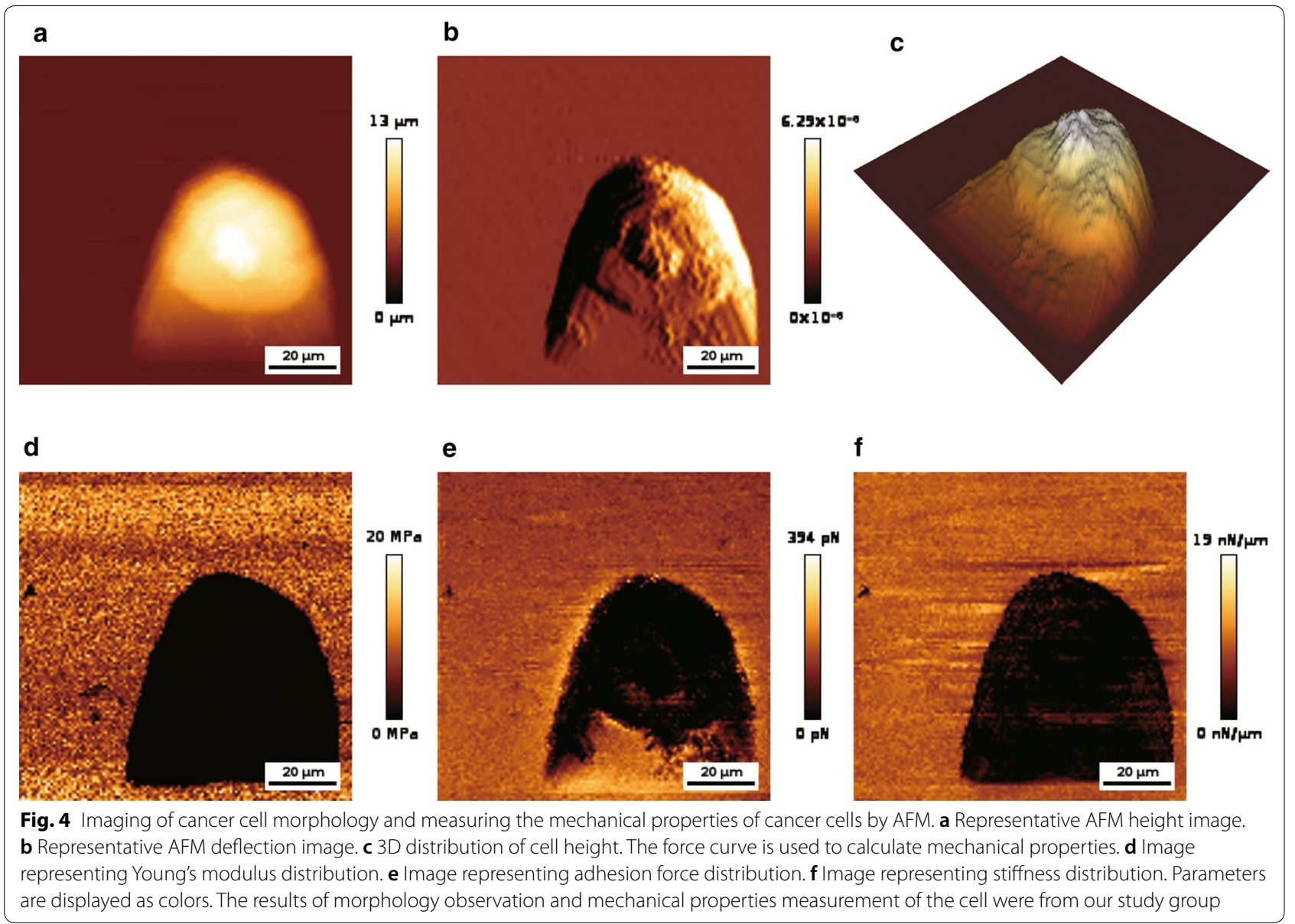

KRAS mutations have a greater degree of radiotherapy resistance [55]. This demonstrated that AFM can be used to detect the ccfDNA fragmentation index in cancer patients, and that this may be used as a potential biomarker for cancer treatment [56-59].

miRNAs play an important role in controlling various cellular processes, and their expression levels can change with disease [60-65]. Northern blotting is a standard method for miRNA quantification, but requires a large amount of RNA for analysis and is insensitive to low abundance RNA $[66,67]$. qRT-PCR is also used to quantitate miRNAs, but the length of miRNAs and primers will, to some extent, hinder their direct detection, which may also be affected by platform differences [68]. Neither of these techniques can be used to perform in situ analysis of miRNAs, or to provide information concerning their subcellular localization. Although nanopore sensors and the single-molecule fluorescence microscopes can be used for single miRNA detection, their sensitivity is not strong [6972]. While enzyme-assisted fluorescence [73], nanoparticle [74], and in situ enrichment (Toehold-initiated rolling circle amplification) [75] techniques can observe single-molecule miRNA, their spatial resolution is poor. AFM, however, is perfect for accurately quantifying miRNA content at the single cell level, allowing for direct and high sensitivity in situ quantification [76]. AFM cannot only quantitate intracellular miRNAs, but can also provide accurate information on their subcellular localization [77]. Therefore, cancer-associated miRNA detection can be performed in situ using AFM, which further extends the diagnostic methods available for cancer [78, 79]. In addition, there are miRNAs in the exosomes secreted by tumor cells which are considered to be related to the development of tumors. These constitute a variety of tumor markers for breast cancer [80-82], colon cancer [83, 84], lung cancer [85], thyroid cancer [86], etc. AFM can be used for imaging analysis of exosomes with different separation modes, and can analyze the effects of different separation methods on the size of exosomes [87]. It can therefore be used to detect cancer diagnosis markers including ccfDNA, miRNA, and exosomes, strongly supplementing existing cancer detection and diagnosis methods. 
In addition, AFM can be used to observe the internal structure of cancer cells. All signaling pathways for cancer cell metastasis go through the nuclear pore complex (NPC), and small molecules can freely pass through NPCs [88]. However, molecules larger than $40 \mathrm{kDa}$ must be combined with FG-Nups to pass through the nuclear pore complex [88]. Using high-speed AFM (HS-AFM), researchers were able to directly observe nano-scale changes in the channels of the nuclear pores in dying colon cancer cells (CRC), and found that these changes were mainly in FG-Nups [89]. This suggested that HSAFM can measure high speed dynamic changes and disordered intracellular systems, and may be used as a cell endoscope to study other organelles in cancer cells. These results showed that AFM can not only measure the morphology and mechanical properties of cells, but can also be used to locate and analyze corresponding molecular and subcellular structures in cancer.

\section{The study of the interaction between molecules}

For cells, AFM can not only provide morphological information on their length, width, and height, but can also be used to study fine structures such as receptors, lipid rafts, and various pathways on membranes. AFM allows researchers to study the activity of unique molecules on individual cells under physiological conditions [90]. By attaching specific molecules (such as ligands and antibodies) to AFM probes, they can locate and manipulate interacting proteins (such as receptors and antigens), using a method called single-molecule force spectroscopy (SMFs) [91, 92] (Fig. 5). This is a powerful supplement to traditional methods to detect the interaction between single molecules [93]. For example, Rituximab is a monoclonal drug for the treatment of leukemia, which is connected to the AFM probe surface [94] to measure the distribution and binding of CD20 and FCR in tumor and NK cells, respectively, and it was found that the binding force of CD20-rituximab is significantly greater than that of FCR-rituximab, the frequency distribution of CD20 in tumor cells was significantly higher than that of FCR on NK cells. The above research suggested that the study of interactions between molecules is feasible by AFM, which can also be used to study the interactions between cancer-related molecules.

Curcumin is a natural polyphenol complex, and a large number of studies have shown that it has an inhibitory effect on many cell lines [95-97], but has no toxic effect on normal cells [98-100]. The CD44 antibody was connected to the AFM probe surface to measure CD44 distribution of the cell surface and the binding force between CD44 and the antibody. Researchers found that the binding force between the CD44 antibody and surface CD44 in human hepatoma cells treated by curcumin was decreased, and the expression of CD44 on cell surfaces was also decreased in unit area [101]. This finding is similar to the results detected by the flow cytometry [101]. a

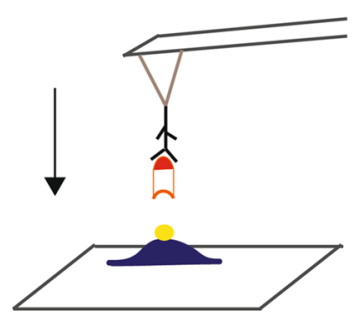

b

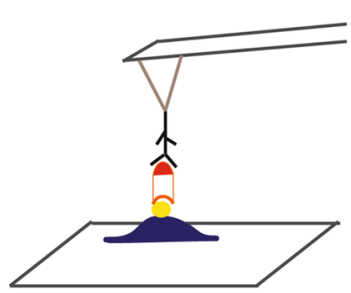

d

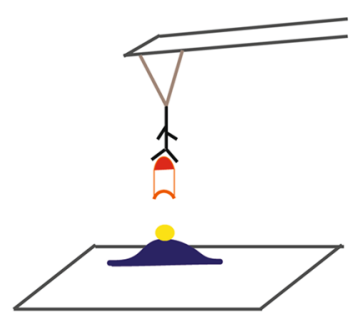

C

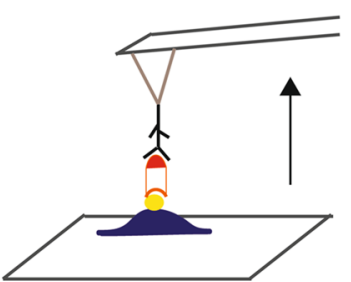

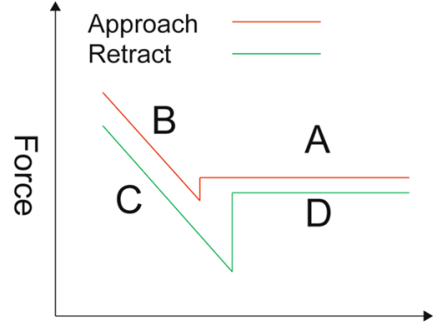

Z Displacement

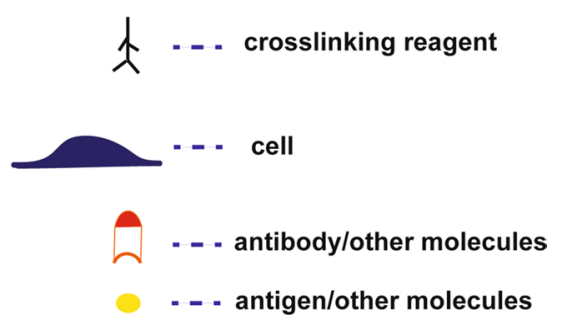

Fig. 5 Schematic diagram of AFM-based single-molecule force spectroscopy. a Individual antibodies or other molecules immobilized on a functionalized tip are positioned above a cell adhering to a substrate. $\mathbf{b}$ Sample and tip molecules are then brought into contact for a defined contact time and with a preset contact force. $\mathbf{c}$ The molecules are subsequently separated, and the maximal separation force and the detachment work can be determined using a simultaneously recorded force-distance curve. $\mathbf{d}$ The cantilever is retracted until the tip and sample molecules separate 
These studies help to explain the relationship between the distribution of CD44 and the apoptosis of cancer cells, as suggest the possibility of tumor therapy by blocking the CD44 molecule on the tumor cell with CD44 antibody. Results of this type show that AFM has good application value in the study of tumor-related molecules.

AFM has many advantages in detecting the interaction between molecules. Compared with traditional methods such as surface plasmon resonance [102], radioimmunoassay [103], and fluorescence resonance energy transfer [104], SMFs can be used to directly measure molecular interactions on the surface of living cells, but in relatively shorter time and at lower cost. The information obtained from SMFs analysis in conjunction with clinical data can help researchers discover biomarkers for efficient tumor prediction and diagnosis.

\section{Evaluation and development of antitumor drugs}

It is of potential value to estimate the effect of anticancer drugs by regulating changes in the morphological and mechanical properties of cancer cells [105-107]. It is generally believed that decreased adhesion of cancer cells is the first step in metastasis. Disulfiram (DSF) is a commonly used clinical hangover drug [108]. However, studies have shown that the DSF-Cu complex has an anti-tumor effect [109]. The stiffness and adhesion of nasopharyngeal carcinoma cells treated with DSF-Cu have been shown to be increased [110], which suggested that DSF-Cu reduces the deformability and enhances the adhesion of these cells. DSF-Cu may, therefore, inhibit the malignant growth and metastasis of nasopharyngeal carcinoma cells.

Changes in the deformability and adhesion of cancer cells may be due to major changes in the morphology and structure of the cell surface following drug treatment. After treatment of colon cancer cells with AEE788 and Celecoxib, their cell surfaces became rough and severely contracted, with pseudopodia and filopodia disappearing completely [111]. The morphology and ultrastructure of Hela and HepG2 cells were also changed after being treated by colchicine and cytidine, and the degree of damage to cancer cells varied with the concentration of the drugs, and the timing of their administration [112]. These findings suggested that the surface morphology of cells can change dramatically after stimulation by drugs or bioactive compounds. In addition, the efficacy of drugs can be judged by their effects on cell surface roughness and hardness. Prostate cancer is a malignant tumor that occurs in the prostate gland of men. Ren et al. evaluated the effects of eight anticancer drugs against this cancer using AFM [113]. They found that the Young's modulus of PC-3 cells increased significantly after treatment with eight drugs, and the mechanism of action of drugs on the mechanical properties of PC-3 cells was different. These studies suggested that AFM can be effectively used in the screening and evaluation of anticancer drugs.

The development of new anti-cancer drugs is essential for the treatment of cancer. Most of the anti-tumor drugs are cytotoxic substances. Due to their poor specificity, they can also cause damage to human normal cells, and may cause strong adverse reactions while providing only low anti-cancer efficiency. Traditional liposomes and nanomaterials have been shown to have good biocompatibility, sustained release, and targeting after being modified and improved, and are the most attractive drug carriers. In evaluating the physical properties and stability of liposomes, AFM is one of the most effective detection technologies [114]. Lapatinib is a dual inhibitor that is used to treat advanced breast cancer and some other cancers [115-117]. Lapatinib is poorly soluble in water, but after being encapsulated in lipoproteins to form nanoparticles (LTNPs), its water solubility increases from $7 \mu \mathrm{g} / \mathrm{mL}$ to $10 \mathrm{mg} /$ $\mathrm{mL}$ or more. AFM measurements showed that LTNPs are spherical particles, and that the height of the particles is not positively correlated with the diameter, as the diameter is about $60 \mathrm{~nm}$ and the height is less than $3 \mathrm{~nm}[118]$.

Carbon nanomaterials are widely used in biomedical devices and biosensors, including carbon nanoparticles (CNP), carbon nanotubes (CNT), and graphene, etc. [119-121]. One study found that carbon nanoparticles $(\mathrm{CB})$ which were covered using BSA and surface-coupled to methotrexate (methotrexate) to form complexes (CBM) were better than methotrexate alone for inhibiting tumor cells [122]. The sizes of CNP, CB, and $\mathrm{CBM}$ were found to range between 16-27, 35-44, and 51-66 nm, respectively, using AFM. Surface morphological changes were found on functionalized $\mathrm{CB}$ and $\mathrm{CBM}$, which was mainly reflected in the significant change in roughness [122]. Similar conformational changes were also found when BSA was bound to CNP $[123,124]$. This indicated that CNP could be used as a nano-carrier to connect anticancer drugs with their corresponding target cells. The surface structure of these nanoparticles or nanocomposites can be quickly determined by AFM [125], allowing for the possible function and work scope of the nano-composites to be predicted.

AFM can assist in the evaluation, screening, and development of anti-cancer drugs. Therapeutic methods that can cause changes in the morphology and mechanical properties of cancer cells can be detected by AFM, which provides an aid for the diagnosis and treatment of cancer. 


\section{AFM in combination with other technologies}

The distal metastasis of cancer is the cause of death in most cancer patients. Understand the differences between primary cancer cells and metastatic cancer cells is therefore critical for the diagnosis and treatment of cancer. At present, it is known that the original cancer cells and metastatic cells have different genetic maps [126, 127], which can be used in clinical diagnosis. It has been shown that Raman spectroscopy can successfully distinguish between cancer and healthy cells, primitive and metastatic cancer cells, and cancerous and healthy tissues [128-131]. The prominent advantage of Raman spectroscopy is that it is possible to know the chemical composition of the substance [132], which is impossible for AFM. However, if AFM and Raman spectroscopy are used together [133], it is possible to not only know the substance content of the cell surface, but to simultaneously determine the substance's chemical composition, thereby enlarging the scope for the use of AFM.

AFM may be combined with a confocal laser scanning microscope (CLSM) to study the mechanical properties of individual cancer cells [134]. The combination of AFM and CLSM directly correlates indentation points with film imaging of subcellular structures [135]. In the early stage of cancer development, the mechanical properties and morphology of cells change. Researchers can detect changes in the elasticity of cancer cells using AFM and elucidate its relationship to malignancy in the early transformation process. Alpha-enolase (ENO1) is a multifunctional protein $[136,137]$ that is not only one of the enzymes involved in glycolysis, but also a fibrinogen receptor that promotes cancer metastasis [138-141]. Combined use of AFM and CLSM revealed that ENO1 gene silencing made pancreatic cancer cells coarser, damaging the adhesion between cancer cells, and between cancer cells and stroma, resulting in the invasion and metastasis of pancreatic cancer cells [142].

Cervical cancer is the second most common cancer in women [143]. Accurate and early diagnosis can reduce costs, greatly benefiting patients. AFM's high resolution imaging of suspected malignant cells can provide more information than light microscopy, targeting cells for accurate diagnosis $[144,145]$. It also provides advantages over scanning electron microscopy (SEM) imaging, allowing for high-resolution 3D imaging, with faster sample preparation, and determining the unique mechanical properties of cells. However, there are limitations to the imaging of cervical cancer cells using either AFM or SEM alone. Multiple forms of detection are more accurate than those provided by a single format test. The imaging diagnosis of cervical carcinoma cells with AFM and SEM has the advantages of fast detection, easy operation, low cost, and so on [146]. SEM and AFM are currently the most common means of surface analysis. However, with AFM, work area selection is very blind, and the work area itself is very limited. Scanning can only be done on the micrometer scale, and it is very difficult to scan larger sample surfaces. Utilizing the large-scale search capabilities of SEM to find and target features or areas of interest that need to be studied by AFM can greatly improve the efficiency of analyses. This system can also be used to detect and diagnose other cancers.

The World Health Organization classifies astrocytomas based on the microscopic appearance of tumors [147]. However, the details of the complex morphology vary according to the specific tumor and patient, and the final classification has to be determined by an experienced pathologist. Therefore, in order to make the classification more accurate, more objective criteria need to be determined. The combined use of AFM imaging and Data Mining Techniques to classify brain tumors is a recentlydeveloped method, achieving $94.74 \%$ classification accuracy in distinguishing between type II, III, and IV tumors [148]. Patients with stage II tumors can quickly be diagnosed using this method, reducing their risk of cancer metastasis.

AFM imaging and mechanical measurement techniques have been widely used in the biomedical field, and allows for the determination of cell structure and function from level of single molecules to that of individual cells. These methods can be used to differentiate between cancer and normal cells at the single-cell level, and enables visual drug research. No technology lacks drawbacks, and AFM technology does have limitations, but its use in combination with other complimentary technologies is a developing trend and is expanding the use of AFM.

\section{Conclusion and prospects}

After nearly 30 years of development, AFM has played an increasingly important role in cell imaging and the study of the mechanical properties of cells. From initial imaging modes (such as contact and tapping imaging modes) and force curve-based mechanical measurement modes to today's high-speed imaging mode (such as fast-scan mode) [149] and high-resolution mechanical measurements modes (such as peak force mode) [150, 151] make AFM increasingly important in the study of cell physicochemical properties. The mechanical properties of cells can be used as a new diagnostic physical biomarker to supplement traditional tissue detection [152]. However, there are still many problems to be solved before the application of AFM technology can be fully realized in practice (for example, in the diagnosis of cancer).

The usage efficiency and the temporal resolution should be improved. At present, AFM measurement 
of cells mainly depends on manual operation, including manual control of the probes to target cells, manual parameter setting to obtain cell force curves, and manual offline processing of experimental data. This leads to very low experimental efficiency, and it takes several minutes to take a measurement of a cell [8]. In particular, in order to obtain statistically significant conclusions, many cells need to be measured, which results in a large workload, and limits the practical application of AFM at the single cell level. Therefore, improving AFM's level of automation will help improve its measurement efficiency. In addition, the response time of the cell to the environment is approximately $1 \mathrm{~ms}$, which is significantly shorter than AFM's mechanical mapping time (about $10 \mathrm{~min}$ ) [153]. This has made it difficult to monitor changes in the mechanical properties of cells in real time. Although HS-AFM has been commercialized [154], with available systems having imaging times of less than $100 \mathrm{~ms}$ [155], and is suitable for imaging rigid and flat small-size samples, such as substrate-bound molecules [156] and microbial cell walls [157], increasing the speed of AFM detection will be of use in real-time studies of changes in the dynamic mechanical properties of cells $[158,159]$. High-speed AFM can also be used for imaging of mammalian cells [160]. The imaging time is, on average, approximately $5 \mathrm{~s}$, far larger than the response time of cells to external stimuli.

The standardization of AFM measurements is another requirement. Young's modulus is a value commonly reported when AFM is used to measure the mechanical properties of cell, but is dependent on the conditions of the experiment, including the environment (temperature, substrate, culture medium) [161], instrument parameters (loading rate, indentation depth) [162], cell (cell position constrained, cell state) [163], data analysis (e.g., pattern selection, contact point determination) [164], and so on. The results of different studies can only be compared when the conditions are in full agreement, and it is difficult for researchers to maintain identical experimental conditions. Therefore, in order to make the measurement results of different research groups comparable, the measurement process needs to be standardized, as does sample treatment.

For clinical and practical applications, multiple clinical cases are needed to verify the reliability of mechanical property detection. Sample preparation and AFM measurements need to be standardized, and the relative values characteristic of cancer cells and normal cells need to be determined. Some studies directly measure the mechanical properties of the original cancer tissue, which allows for detection of the different stages of tumor metastasis $[165,166]$. However, tumor tissue includes cancerous cells, normal cells, blood vessels, and extracellular matrix [167], which means that such measurements describe the mechanical properties of the local tissue, and not of isolated cancer cells. The most difficult part of the measurement is to determine the contribution of each component to the mechanical properties of cancerous tissue. Studies have shown that other non-tumor cells in tumor tissues also affect the development and metastasis of tumors [168]. In addition, tumor tissue is highly heterogeneous, with differences manifesting in different tumor tissues as well as in different parts of the same tissue [169]. Therefore, tumor tissues in different locations may have different mechanical properties, and different parts of the tissue need to be extracted for comparative detection.

In recent years, many AFM models have been developed [170-172]. Together with advances in complementary techniques (Table 2), this will allow AFM to

Table 2 Comparison of high-resolution imaging techniques in molecular and cell biology [171]

\begin{tabular}{|c|c|c|c|c|}
\hline $\begin{array}{l}\text { Technique/ } \\
\text { feature }\end{array}$ & Atomic force microscopy & $\begin{array}{l}\text { Super-resolution microscopy } \\
\text { (STED, PALM, STORM) }\end{array}$ & $\begin{array}{l}\text { Transmission electron } \\
\text { microscopy }\end{array}$ & $\begin{array}{l}\text { Scanning election } \\
\text { microscopy }\end{array}$ \\
\hline Resolution & $\leq 1 \mathrm{~nm}-50 \mathrm{~nm}$ & $20-50 \mathrm{~nm}$ & $0.2-10 \mathrm{~nm}$ & $2-10 \mathrm{~nm}$ \\
\hline $\begin{array}{l}\text { Sample prepa- } \\
\text { ration and } \\
\text { environment }\end{array}$ & $\begin{array}{l}\text { Sample on support; physiological } \\
\text { (buffer solution, temperature, } \\
\left(\mathrm{CO}_{2}\right)\end{array}$ & $\begin{array}{l}\text { Fluorescence labelling; } \\
\text { physiological (buffer solution, } \\
\left.\text { temperature, } \mathrm{CO}_{2}\right)\end{array}$ & $\begin{array}{l}\text { Sample on grid; dehydrated } \\
\text { (negative stain); vitrified } \\
\text { (cryo-electron microscopy) }\end{array}$ & $\begin{array}{l}\text { Freeze/critical point drying } \\
\text { and metal shadowing }\end{array}$ \\
\hline Artefacts & Tip, force, scanning & Bleaching, toxicity & $\begin{array}{l}\text { Dehydration, ice crystal forma- } \\
\text { tion, beam damage }\end{array}$ & $\begin{array}{l}\text { Dehydration, metal shadow- } \\
\text { ing, beam damage }\end{array}$ \\
\hline Advantages & $\begin{array}{l}\text { Imaging under native conditions; } \\
\text { no staining, labelling, or fixation } \\
\text { necessary; high signal-to-noise } \\
\text { ratio; assessment of multiple } \\
\text { physical, chemical, and biologi- } \\
\text { cal parameters }\end{array}$ & $\begin{array}{l}\text { Access to three-dimensional } \\
\text { cellular structures; high } \\
\text { spatiotemporal resolution; } \\
\text { monitoring biomolecular } \\
\text { processes in life cells }\end{array}$ & $\begin{array}{l}\text { Solves atomic structures of } \\
\text { proteins; conformational } \\
\text { snapshot of proteins and } \\
\text { complexes; molecular resolu- } \\
\text { tion of structures within } \\
\text { the cell }\end{array}$ & $\begin{array}{l}\text { Imaging surfaces of tissues, } \\
\text { cells, and interfaces as } \\
\text { nanometer-scale resolution }\end{array}$ \\
\hline Limitation & Restricted to surfaces & $\begin{array}{l}\text { Imaging restricted to fluores- } \\
\text { cence labels }\end{array}$ & No life processes & No life processes \\
\hline
\end{tabular}


address outstanding questions in biology in the coming decades. These have made the AFM easier to apply to biological systems, which has resulted in more information on these systems being generated.

Currently, the sensitivity and temperature stability (drift) of AFM limits its accuracy in describing biological systems. The recently introduced ultra-stable AFM can provide the accuracy of sub-pico force while providing high stability $(<0.03 \AA)$ at very low lateral drift $(\sim 5 \mathrm{pm} \min )[173,174]$. We predict that with the continuous development and improvement of AFM technology, it will play an increasingly important role in cancer research and diagnosis.

\begin{abstract}
Abbreviations
AFM: atomic force microscopy; CB: carbon nanoparticles coated in BSA; CBM: carbon nanoparticles coupled to methotrexate; ccfDNA: circulating cell-free DNA; CLSM: confocal laser scanning microscope; CNP: carbon nanoparticles; CRC: colon cancer cells; CNT: carbon nanotubes; DSF: disulfiram; HS-AFM: high-speed AFM; LTFNs: lipoproteins to form nanoparticles; NPC: nuclear pore complex; SMFs: single-molecule force spectroscopy; VEGF-D: vascular endothelial growth factor D; VEGF-C: vascular endothelial growth factor $C_{i}$; ECM: extracellular matrix
\end{abstract}

\section{Authors' contributions}

$X D, F X, X L, B X, Z L, X W, C G, X L, Y L$ and $G L$ collected the related paper and drafted the manuscript. WX, and ZZ participated in the design of the review and draft the manuscript. All authors read and approved the final manuscript.

\section{Author details}

${ }^{1}$ The Key Laboratory of Carcinogenesis of the Chinese Ministry of Health and Hunan Key Laboratory of Translational Radiation Oncology, Hunan Cancer Hospital and The Affiliated Cancer Hospital of Xiangya School of Medicine, Central South University, Changsha 410013, Hunan, China. ${ }^{2}$ The Key Laboratory of Carcinogenesis and Cancer Invasion of the Chinese Ministry of Education, Cancer Research Institute and School of Basic Medical Science, Xiangya School of Medicine, Central South University, Changsha 410078, China.

${ }^{3}$ Hunan Key Laboratory of Nonresolving Inflammation and Cancer, Disease Genome Research Center, The Third Xiangya Hospital, Central South University, Changsha 410013, Hunan, China. ${ }^{4}$ Department of Chemistry, University of North Dakota, Grand Forks, ND 58202, USA. ${ }^{5}$ Department of Cancer Biology, Lerner Research Institute, Cleveland Clinic, Cleveland, OH 44195, USA.

\section{Acknowledgements}

Not applicable.

\section{Competing interests}

The authors declare that they have no competing interests.

\section{Availability of data and materials}

Not applicable.

\section{Consent for publication}

All authors have read and approved this publication.

Ethics approval and consent to participate

Not applicable.

\section{Funding}

This work was supported in part by grants from the National Natural Science Foundation of China $(81572787,81672683,81672993,81772928,81702907$, $81772901,31741049,21806186,81803025$ and 81872278), the Overseas Expertise Introduction Project for Discipline Innovation (111 Project, No. 111 2-12), and the Natural Science Foundation of Hunan Province (2016JC2035, 2017SK2105, 2018JJ3815, 2018JJ3704, 2018SK21210 and 2018SK21211).

\section{Publisher's Note}

Springer Nature remains neutral with regard to jurisdictional claims in published maps and institutional affiliations.

Received: 4 October 2018 Accepted: 24 November 2018

Published online: 11 December 2018

\section{References}

1. Friedl $P$, Wolf $K$. Tumour-cell invasion and migration: diversity and escape mechanisms. Nat Rev Cancer. 2003;3:362-74.

2. Wei F, Wu Y, Tang L, Xiong F, Guo C, Li X, et al. Trend analysis of cancer incidence and mortality in China. Sci China Life Sci. 2017;60:1271-5.

3. Lian Y, Xiong F, Yang L, Bo H, Gong Z, Wang Y, et al. Long noncoding RNA AFAP1-AS1 acts as a competing endogenous RNA of miR-423-5p to facilitate nasopharyngeal carcinoma metastasis through regulating the Rho/Rac pathway. J Exp Clin Cancer Res. 2018;37:253.

4. Wei F, Wu Y, Tang L, He Y, Shi L, Xiong F, et al. BPIFB1 (LPLUNC1) inhibits migration and invasion of nasopharyngeal carcinoma by interacting with VTN and VIM. Br J Cancer. 2018;118:233-47.

5. Binnig G, Quate CF, Gerber C. Atomic force microscope. Phys Rev Lett. 1986:56:930-3.

6. Lal R, Ramachandran S, Arnsdorf MF. Multidimensional atomic force microscopy: a versatile novel technology for nanopharmacology research. AAPS J. 2010;12:716-28.

7. Yang F, Riedel R, Del Pino P, Pelaz B, Said AH, Soliman M, Pinnapireddy SR, Feliu N, Parak WJ, Bakowsky U, Hampp N. Real-time, label-free monitoring of cell viability based on cell adhesion measurements with an atomic force microscope. J Nanobiotechnol. 2017;15:23.

8. Di Carlo D. A mechanical biomarker of cell state in medicine. J Lab Autom. 2012;17:32-42.

9. Li Q, Chen P, Zeng Z, Liang F, Song Y, Xiong F, et al. Yeast two-hybrid screening identified WDR77 as a novel interacting partner of TSC22D2. Tumour Biol. 2016:37:12503-12.

10. Liang F, Li Q, Li X, Li Z, Gong Z, Deng H, et al. TSC22D2 interacts with PKM2 and inhibits cell growth in colorectal cancer. Int J Oncol. 2016:49:1046-56.

11. Wang $Y$, Xue D, Li Y, Pan $X$, Zhang $X$, Kuang $B$, et al. The long noncoding RNA MALAT-1 is a novel biomarker in various cancers: a meta-analysis based on the GEO database and literature. J Cancer. 2016;7:991-1001.

12. Yu J, Liu Y, Gong Z, Zhang S, Guo C, Li X, et al. Overexpression long non-coding RNA LINC00673 is associated with poor prognosis and promotes invasion and metastasis in tongue squamous cell carcinoma. Oncotarget. 2017:8:16621-32.

13. Yu J, Liu Y, Guo C, Zhang S, Gong Z, Tang Y, et al. Upregulated long non-coding RNA LINC00152 expression is associated with progression and poor prognosis of tongue squamous cell carcinoma. J Cancer. 2017:8:523-30.

14. Rodriguez ML, Mcgarry PJ, Sniadecki NJ. Review on cell mechanics: experimental and modeling approaches. Appli Mech Rev. 2013;65:60801.

15. Moeendarbary E, Harris AR. Cell mechanics: principles, practices, and prospects. Wiley Interdiscip Rev Syst Biol Med. 2014;6:371-88.

16. Kollmannsberger P, Fabry B. Linear and nonlinear rheology of living cells. Ann Rev Mater Res. 2011;41:75-97.

17. Zhao X, Zhong Y, Ye T, Wang D, Mao B. Discrimination between cervical cancer cells and normal cervical cells based on longitudinal elasticity using atomic force microscopy. Nanoscale Res Lett. 2015;10:1-8.

18. He Y, Jing $Y$, Wei F, Tang Y, Yang L, Luo J, et al. Long non-coding RNA PVT1 predicts poor prognosis and induces radioresistance by regulating DNA repair and cell apoptosis in nasopharyngeal carcinoma. Cell Death Dis. 2018:9:235.

19. Tang L, Wei F, Wu Y, He Y, Shi L, Xiong F, et al. Role of metabolism in cancer cell radioresistance and radiosensitization methods. J Exp Clin Cancer Res. 2018;37:87.

20. Tang $Y$, He Y, Zhang $P$, Wang J, Fan $C$, Yang L, et al. LncRNAs regulate the cytoskeleton and related Rho/ROCK signaling in cancer metastasis. Mol Cancer. 2018;17:77. 
21. Wei F, Tang L, He Y, Wu Y, Shi L, Xiong F, et al. BPIFB1 (LPLUNC1) inhibits radioresistance in nasopharyngeal carcinoma by inhibiting VTN expression. Cell Death Dis. 2018;9:432.

22. Zhang $\mathrm{Y}$, Xia M, Jin K, Wang S, Wei H, Fan C, et al. Function of the c-Met receptor tyrosine kinase in carcinogenesis and associated therapeutic opportunities. Mol Cancer. 2018;17:45.

23. Wang $Y A$, Li XL, Mo YZ, Fan CM, Tang L, Xiong F, et al. Effects of tumor metabolic microenvironment on regulatory T cells. Mol Cancer. 2018:17:168.

24. Dufrene YF, Pelling AE. Force nanoscopy of cell mechanics and cell adhesion. Nanoscale. 2013:5:4094-104.

25. Fan C, Tang Y, Wang J, Wang Y, Xiong F, Zhang S, et al. Long non-coding RNA LOC284454 promotes migration and invasion of nasopharyngeal carcinoma via modulating the Rho/Rac signaling pathway. Carcinogenesis. 2018. https://doi.org/10.1093/carcin/bgy 143 .

26. Minelli E, Ciasca G, Sassun TE, Antonelli M, Palmieri V, Papi M, Maulucci G, Santoro A, Giangaspero F, Delfini RJ. A fully-automated neural network analysis of AFM force-distance curves for cancer tissue diagnosis. Appl Phys Lett. 2017;111:143701

27. Fan C, Tang Y, Wang J, Xiong F, Guo C, Wang Y, et al. Role of long noncoding RNAs in glucose metabolism in cancer. Mol Cancer. 2017;16:130.

28. Tu C, Zeng Z, Qi P, Li X, Yu Z, Guo C, et al. Genome-wide analysis of 18 Epstein-Barr viruses isolated from primary nasopharyngeal carcinoma biopsy specimens. J Virol. 2017:91:e00301-17.

29. Wang JP, Tang YY, Fan CM, Guo C, Zhou YH, Li Z, et al. The role of exosomal non-coding RNAs in cancer metastasis. Oncotarget. 2018:9:12487-502.

30. Yang L, Tang Y, Xiong F, He Y, Wei F, Zhang S, et al. LncRNAs regulate cancer metastasis via binding to functional proteins. Oncotarget. 2018:9:1426-43

31. Gaman A, Osiac E, Rotaru I, Taisescu C. Surface morphology of leukemic cells from chronic myeloid leukemia under atomic force microscopy. Curr Health Sci J. 2013;39:45-7.

32. Kaul-Ghanekar R, Singh S, Mamgain H, Jalota-Badhwar A, Paknikar KM, Chattopadhyay S. Tumor suppressor protein SMAR1 modulates the roughness of cell surface: combined AFM and SEM study. BMC Cancer. 2009;9:350

33. Bo H, Fan L, Li J, Liu Z, Zhang S, Shi L, et al. High expression of IncRNA AFAP1-AS1 promotes the progression of colon cancer and predicts poor prognosis. J Cancer. 2018;9:4677-83.

34. Tu C, Zeng Z, Qi P, Li X, Guo C, Xiong F, et al. Identification of genomic alterations in nasopharyngeal carcinoma and nasopharyngeal carcinoma-derived Epstein-Barr virus by whole genome sequencing. Carcinogenesis. 2018. https://doi.org/10.1093/carcin/bgy108.

35. Gross I, Duluc I, Benameur T, Calon A, Martin E, Brabletz T, Kedinger M, Domon-Dell C, Freund JN. The intestine-specific homeobox gene C $\mathrm{dx2}$ decreases mobility and antagonizes dissemination of colon cancer cells. Oncogene. 2008;27:107-15.

36. Mallo GV, Soubeyran P, Lissitzky JC, Andre F, Farnarier C, Marvaldi J, Dagorn JC, lovanna JL. Expression of the $\mathrm{Cd} \times 1$ and $\mathrm{Cd} \times 2$ homeotic genes leads to reduced malignancy in colon cancer-derived cells. J Biol Chem. 1998;273:14030-6.

37. Aoki K, Tamai Y, Horiike S, Oshima M, Taketo MM. Colonic polyposis caused by mTOR-mediated chromosomal instability in Apc+/Delta716 Cdx2士 compound mutant mice. Nat Genet. 2003:35:323-30.

38. Bonhomme C, Duluc I, Martin E, Chawengsaksophak K, Chenard MP, Kedinger M, Beck F, Freund JN, Domon-Dell C. The Cdx2 homeobox gene has a tumour suppressor function in the distal colon in addition to a homeotic role during gut development. Gut. 2003:52:1465-71.

39. Hryniuk A, Grainger S, Savory JG, Lohnes D. Cdx1 and Cdx2 function as tumor suppressors. J Biol Chem. 2014;289:33343-54.

40. Platet N, Hinkel I, Richert L, Murdamoothoo D, Moufok-Sadoun A Vanier M, Lavalle P, Gaiddon C, Vautier D, Freund JN, Gross I. The tumor suppressor CDX2 opposes pro-metastatic biomechanical modifications of colon cancer cells through organization of the actin cytoskeleton. Cancer Lett. 2017:386:57-64.

41. Cao R, Ji H, Feng N, Zhang Y, Yang X, Andersson P, Sun Y, Tritsaris $K$, Hansen AJ, Dissing S, Cao Y. Collaborative interplay between FGF-2 and VEGF-C promotes lymphangiogenesis and metastasis. Proc Natl Acad Sci USA. 2012;109:15894-9.
42. Liu B, Ma J, Wang X, Su F, Li X, Yang S, Ma W, Zhang Y. Lymphangiogenesis and its relationship with lymphatic metastasis and prognosis in malignant melanoma. Anat Rec (Hoboken). 2008;291:1227-35.

43. Fraley SI, Feng Y, Krishnamurthy R, Kim DH, Celedon A, Longmore GD, Wirtz D. A distinctive role for focal adhesion proteins in three-dimensional cell motility. Nat Cell Biol. 2010;12:598-604.

44. Cross SE, Jin YS, Rao J, Gimzewski JK. Nanomechanical analysis of cells from cancer patients. Nat Nanotechnol. 2007;2:780-3.

45. Xu W, Mezencev R, Kim B, Wang L, McDonald J, Sulchek T. Cell stiffness is a biomarker of the metastatic potential of ovarian cancer cells. PLoS ONE. 2012;7:e46609.

46. Cross SE, Jin YS, Tondre J, Wong R, Rao J, Gimzewski JK. AFM-based analysis of human metastatic cancer cells. Nanotechnology. 2008;19:384003.

47. Lekka M, Laidler P, Gil D, Lekki J, Stachura Z, Hrynkiewicz AZ. Elasticity of normal and cancerous human bladder cells studied by scanning force microscopy. Eur Biophys J. 1999;28:312-6.

48. Li QS, Lee GY, Ong CN, Lim CT. AFM indentation study of breast cancer cells. Biochem Biophys Res Commun. 2008;374:609-13.

49. Jorba I, Uriarte JJ, Campillo N, Farre R, Navajas D. Probing micromechanical properties of the extracellular matrix of soft tissues by atomic force microscopy. J Cell Physiol. 2017;232:19-26.

50. Gang Z, Qi Q, Jing C, Wang C. Measuring microenvironment mechanical stress of rat liver during diethylnitrosamine induced hepatocarcinogenesis by atomic force microscope. Microsc Res Tech. 2009;72:672-8.

51. Guck J, Schinkinger S, Lincoln B, Wottawah F, Ebert S, Romeyke M, et al. Optical deformability as an inherent cell marker for testing malignant transformation and metastatic competence. Biophys J. 2005:88:3689-98.

52. Schwarzenbach H, Hoon DS, Pantel K. Cell-free nucleic acids as biomarkers in cancer patients. Nat Rev Cancer. 2011;11:426-37.

53. Stroun M, Lyautey J, Lederrey C, Olson-Sand A, Anker P. About the possible origin and mechanism of circulating DNA apoptosis and active DNA release. Clin Chim Acta. 2001;313:139-42.

54. Mouliere F, El Messaoudi S, Pang D, Dritschilo A, Thierry AR. Multimarker analysis of circulating cell-free DNA toward personalized medicine for colorectal cancer. Mol Oncol. 2014;8:927-41.

55. Janowski E, Timofeeva O, Chasovskikh S, Goldberg M, Kim A, Banovac F, Pang D, Dritschilo A, Unger K. Yttrium-90 radioembolization for colorectal cancer liver metastases in KRAS wild-type and mutant patients: clinical and ccfDNA studies. Oncol Rep. 2017;37:57-65.

56. He R, Liu P, Xie X, Zhou Y, Liao Q, Xiong W, Li X, Li G, Zeng Z, Tang H. circGFRA1 and GFRA1 act as ceRNAs in triple negative breast cancer by regulating miR-34a. J Exp Clin Cancer Res. 2017;36:145.

57. Wang $Y, M o Y$, Gong Z, Yang $X$, Yang $M$, Zhang $S$, et al. Circular RNAs in human cancer. Mol Cancer. 2017:16:25.

58. Zhong Y, Du Y, Yang X, Mo Y, Fan C, Xiong F, et al. Circular RNAs function as ceRNAs to regulate and control human cancer progression. Mol Cancer. 2018;17:79.

59. Zhou R, Wu Y, Wang W, Su W, Liu Y, Wang Y, et al. Circular RNAs (circRNAs) in cancer. Cancer Lett. 2018:425:134-42.

60. Yan Q, Zeng Z, Gong Z, Zhang W, Li X, He B, et al. EBV-miR-BART10-3p facilitates epithelial-mesenchymal transition and promotes metastasis of nasopharyngeal carcinoma by targeting BTRC. Oncotarget. 2015;6:41766-82.

61. Gong Z, Yang Q, Zeng Z, Zhang W, Li X, Zu X, et al. An integrative transcriptomic analysis reveals p53 regulated miRNA, mRNA, and IncRNA networks in nasopharyngeal carcinoma. Tumour Biol. 2016;37:3683-95.

62. He B, Li W, Wu Y, Wei F, Gong Z, Bo H, et al. Epstein-Barr virus-encoded miR-BART6-3p inhibits cancer cell metastasis and invasion by targeting long non-coding RNA LOC553103. Cell Death Dis. 2016;7:e2353.

63. Song Y, Li X, Zeng Z, Li Q, Gong Z, Liao Q, et al. Epstein-Barr virus encoded miR-BART11 promotes inflammation-induced carcinogenesis by targeting FOXP1. Oncotarget. 2016;7:36783-99.

64. Xiao K, Yu Z, Li X, Li X, Tang K, Tu C, et al. Genome-wide analysis of Epstein-Barr virus (EBV) integration and strain in C666-1 and raji cells. J Cancer. 2016;7:214-24.

65. Fan C, Tang Y, Wang J, Xiong F, Guo C, Wang Y, et al. The emerging role of Epstein-Barr virus encoded microRNAs in nasopharyngeal carcinoma. J Cancer. 2018;9:2852-64. 
66. Hunt EA, Broyles D, Head T, Deo SK. MicroRNA detection: current technology and research strategies. Annu Rev Anal Chem (Palo Alto Calif). 2015;8:217-37.

67. Dong H, Lei J, Ding L, Wen Y, Ju H, Zhang X. MicroRNA: function, detection, and bioanalysis. Chem Rev. 2013;113:6207-33.

68. Mestdagh P, Hartmann N, Baeriswyl L, Andreasen D. Evaluation of quantitative miRNA expression platforms in the microRNA quality control (miRQC) study. Nat Methods. 2014;11:809-15.

69. Wanunu M, Dadosh T, Ray V, Jin J, McReynolds L, Drndic M. Rapid electronic detection of probe-specific microRNAs using thin nanopore sensors. Nat Nanotechnol. 2010;5:807-14.

70. Wang Y, Zheng D, Tan Q, Wang MX, Gu LQ. Nanopore-based detection of circulating microRNAs in lung cancer patients. Nat Nanotechnol. 2011;6:668-74.

71. Neely LA, Patel S, Garver J, Gallo M, Hackett M, McLaughlin S, Nadel M, Harris J, Gullans S, Rooke J. A single-molecule method for the quantitation of microRNA gene expression. Nat Methods. 2006;3:41-6.

72. Chan HM, Chan LS, Wong RN, Li HW. Direct quantification of singlemolecules of microRNA by total internal reflection fluorescence microscopy. Anal Chem. 2010;82:6911-8.

73. Lu J, Tsourkas A. Imaging individual microRNAs in single mammalian cells in situ. Nucleic Acids Res. 2009;37:e100.

74. Zhang J, Fu Y, Mei Y, Jiang F, Lakowicz JR. Fluorescent metal nanoshell probe to detect single miRNA in lung cancer cell. Anal Chem. 2010;82:4464-71.

75. Deng R, Tang L, Tian Q, Wang Y, Lin L, Li J. Toehold-initiated rolling circle amplification for visualizing individual microRNAs in situ in single cells. Angew Chem Int Ed Engl. 2014;53:2389-93.

76. Koo H, Park I, Lee Y, Kim HJ, Jung JH, Lee JH, Kim Y, Kim JH, Park JW. Visualization and quantification of MicroRNA in a single cell using atomic force microscopy. J Am Chem Soc. 2016;138:11664-71.

77. Nowotny M, Cerritelli SM, Ghirlando R, Gaidamakov SA, Crouch RJ, Yang W. Specific recognition of RNA/DNA hybrid and enhancement of human RNase $\mathrm{H1}$ activity by HBD. EMBO J. 2008;27:1172-81.

78. Lujambio A, Lowe SW. The microcosmos of cancer. Nature. 2012:482:347-55.

79. Kasinski AL, Slack FJ. Epigenetics and genetics MicroRNAs en route to the clinic: progress in validating and targeting microRNAs for cancer therapy. Nat Rev Cancer. 2011;11:849-64

80. Chen WX, Cai YQ, Lv MM, Chen L, Zhong SL, Ma TF, Zhao JH, Tang JH. Exosomes from docetaxel-resistant breast cancer cells alter chemosensitivity by delivering microRNAs. Tumour Biol. 2014;35:9649-59.

81. Hannafon BN, Carpenter KJ, Berry WL, Janknecht R, Dooley WC, Ding WQ. Exosome-mediated microRNA signaling from breast cancer cells is altered by the anti-angiogenesis agent docosahexaenoic acid (DHA). Mol Cancer. 2015;14:133.

82. Melo SA, Sugimoto H, O'Connell JT, Kato N, Villanueva A, Vidal A, et al. Cancer exosomes perform cell-independent microRNA biogenesis and promote tumorigenesis. Cancer Cell. 2014;26:707-21.

83. Yan S, Dang G, Zhang X, Jin C, Qin L, Wang Y, Shi M, Huang H, Duan Q. Downregulation of circulating exosomal miR-638 predicts poor prognosis in colon cancer patients. Oncotarget. 2017;8:72220-6.

84. Hosseini M, Khatamianfar S, Hassanian SM, Nedaeinia R, Shafiee M, Maftouh M, Ghayour-Mobarhan M, ShahidSales S, Avan A. ExosomeEncapsulated microRNAs as potential circulating biomarkers in colon cancer. Curr Pharm Des. 2017;23:1705-9.

85. Fujita Y, Kuwano K, Ochiya T, Takeshita F. The impact of extracellular vesicle-encapsulated circulating microRNAs in lung cancer research. Biomed Res Int. 2014;2014:486413.

86. Lee JC, Zhao JT, Gundara J, Serpell J, Bach LA, Sidhu S. Papillary thyroid cancer-derived exosomes contain miRNA-146b and miRNA-222. J Surg Res. 2015;196:39-48.

87. Woo J, Sharma S, Gimzewski J. The role of isolation methods on a nanoscale surface structure and its effect on the size of exosomes. J Circ Biomark. 2016;5:11.

88. Funasaka T, Wong RW. The role of nuclear pore complex in tumor microenvironment and metastasis. Cancer Metastasis Rev. 2011;30:239-51.

89. Mohamed MS, Kobayashi A, Taoka A, Watanabe-Nakayama T, Kikuchi Y, Hazawa M, et al. High-speed atomic force microscopy reveals loss of nuclear pore resilience as a dying code in colorectal cancer cells. ACS Nano. 2017;11:5567-78.

90. Taatjes DJ, Quinn AS, Rand JH, Jena BP. Atomic force microscopy: high resolution dynamic imaging of cellular and molecular structure in health and disease. J Cell Physiol. 2013;228:1949-55.

91. Zlatanova J, Lindsay SM, Leuba SH. Single molecule force spectroscopy in biology using the atomic force microscope. Prog Biophys Mol Biol. 2000;74:37-61.

92. Muller DJ, Helenius J, Alsteens D, Dufrene YF. Force probing surfaces of living cells to molecular resolution. Nat Chem Biol. 2009;5:383-90.

93. Muller DJ, Dufrene YF. Force nanoscopy of living cells. Curr Biol. 2011:21:R212-6.

94. Hinterdorfer P, Dufrene YF. Detection and localization of single molecular recognition events using atomic force microscopy. Nat Methods. 2006:3:347-55.

95. Sen S, Sharma H, Singh N. Curcumin enhances Vinorelbine mediated apoptosis in NSCLC cells by the mitochondrial pathway. Biochem Biophys Res Commun. 2005:331:1245-52.

96. Holy JM. Curcumin disrupts mitotic spindle structure and induces micronucleation in MCF-7 breast cancer cells. Mutat Res. 2002;518:71-84

97. Aggarwal BB, Kumar A, Bharti AC. Anticancer potential of curcumin: preclinical and clinical studies. Anticancer Res. 2003;23:363-98.

98. Hatcher H, Planalp R, Cho J, Torti FM, Torti SV. Curcumin: from ancient medicine to current clinical trials. Cell Mol Life Sci. 2008:65:1631-52.

99. Kunwar A, Barik A, Mishra B, Rathinasamy K, Pandey R, Priyadarsini KI. Quantitative cellular uptake, localization and cytotoxicity of curcumin in normal and tumor cells. Biochim Biophys Acta. 2008;1780:673-9.

100. Syng-Ai C, Kumari AL, Khar A. Effect of curcumin on normal and tumor cells: role of glutathione and bcl-2. Mol Cancer Ther. 2004;3:1101-8.

101. Wang M, Ruan Y, Xing X, Chen Q, Peng Y, Cai J. Curcumin induced nanoscale CD44 molecular redistribution and antigen-antibody interaction on HepG2 cell surface. Anal Chim Acta. 2011;697:83-9.

102. Bruhns $P$, lannascoli $B$, England $P$, Mancardi DA, Fernandez N, Jorieux S, Daeron M. Specificity and affinity of human Fcgamma receptors and their polymorphic variants for human IgG subclasses. Blood. 2009;113:3716-25.

103. Li B, Zhao L, Guo H, Wang C, Zhang X, Wu L, Chen L, Tong Q, Qian W, Wang $\mathrm{H}$, Guo Y. Characterization of a rituximab variant with potent antitumor activity against rituximab-resistant B-cell lymphoma. Blood. 2009;114:5007-15.

104. Bucherl C, Aker J, de Vries S, Borst JW. Probing protein-protein Interactions with FRET-FLIM. Methods Mol Biol. 2010;655:389-99.

105. Bour-Dill C, Gramain MP, Merlin JL, Marchal S, Guillemin F. Determination of intracellular organelles implicated in daunorubicin cytoplasmic sequestration in multidrug-resistant MCF-7 cells using fluorescence microscopy image analysis. Cytometry. 2000;39:16-25.

106. Hung MS, Tsai MF. Investigating the influence of anti-cancer drugs on the mechanics of cells using AFM. Bionanoscience. 2015:5:156-61.

107. Qin Y, Chen K, Gu W, Dong X, Lei R, Chang Y, et al. Small size fullerenol nanoparticles suppress lung metastasis of breast cancer cell by disrupting actin dynamics. J Nanobiotechnology. 2018;16:54.

108. Barth KS, Malcolm RJ. Disulfiram: an old therapeutic with new applications. CNS Neurol Disord: Drug Targets. 2010;9:5-12.

109. Cvek B. Targeting malignancies with disulfiram (Antabuse): multidrug resistance, angiogenesis, and proteasome. Curr Cancer Drug Targets. 2011:11:332-7.

110. Yang Y, Li M, Sun X, Zhou C, Wang Y, Wang L, Chen L, Liang Z, Zhu L, Yang $\mathrm{H}$. The selective cytotoxicity of DSF-Cu attributes to the biomechanical properties and cytoskeleton rearrangements in the normal and cancerous nasopharyngeal epithelial cells. Int J Biochem Cell Biol. 2017:84:96-108.

111. Venkatesan P, Das S, Krishnan MM, Chakraborty C, Chaudhury K, Mandal M. Effect of AEE788 and/or Celecoxib on colon cancer cell morphology using advanced microscopic techniques. Micron. 2010;41:247-56.

112. Wang J, Wan Z, Liu W, Li L, Ren L, Wang X, et al. Atomic force microscope study of tumor cell membranes following treatment with anticancer drugs. Biosens Bioelectron. 2009;25:721-7.

113. Ren J, Huang H, Liu Y, Zheng X, Zou Q. An atomic force microscope study revealed two mechanisms in the effect of anticancer drugs on 
rate-dependent young's modulus of human prostate cancer cells. PLoS ONE. 2015;10:e0126107.

114. Spyratou E, Mourelatou EA, Makropoulou M, Demetzos C. Atomic force microscopy: a tool to study the structure, dynamics and stability of liposomal drug delivery systems. Expert Opin Drug Deliv. 2009;6:305-17.

115. LaBonte MJ, Wilson PM, Fazzone W, Russell J, Louie SG, El-Khoueiry A, Lenz HJ, Ladner RD. The dual EGFR/HER2 inhibitor lapatinib synergistically enhances the antitumor activity of the histone deacetylase inhibitor panobinostat in colorectal cancer models. Cancer Res. 2011;71:3635-48

116. Gao H, Yang Z, Cao S, Xi Z, Zhang S, Pang Z, Jiang X. Behavior and antiglioma effect of lapatinib-incorporated lipoprotein-like nanoparticles. Nanotechnology. 2012;23:435101.

117. Olaussen KA, Commo F, Tailler M, Lacroix L, Vitale I, Raza SQ, Richon C, Dessen P, Lazar V, Soria JC, Kroemer G. Synergistic proapoptotic effects of the two tyrosine kinase inhibitors pazopanib and lapatinib on multiple carcinoma cell lines. Oncogene. 2009;28:4249-60.

118. Zhang L, Zhang S, Ruan SB, Zhang QY, He Q, Gao HL. Lapatinib-incorporated lipoprotein-like nanoparticles: preparation and a proposed breast cancer-targeting mechanism. Acta Pharmacol Sin. 2014;35:846-52.

119. Moghimi SM, Hunter AC, Murray JC. Nanomedicine: current status and future prospects. FASEB J. 2005;19:311-30.

120. Surendiran A, Sandhiya S, Pradhan SC, Adithan C. Novel applications of nanotechnology in medicine. Indian J Med Res. 2009;130:689-701.

121. Bosi S, Da Ros T, Spalluto G, Prato M. Fullerene derivatives: an attractive tool for biological applications. Eur J Med Chem. 2003;38:913-23.

122. Muthukumar T, Prabhavathi S, Chamundeeswari M, Sastry TP. Bio-modified carbon nanoparticles loaded with methotrexate possible carrier for anticancer drug delivery. Mater Sci Eng C Mater Biol Appl. 2014;36:14-9.

123. Goldberg-Oppenheimer P, Regev O. Exploring a nanotube dispersion mechanism with gold-labeled proteins via cryo-TEM imaging. Small. 2007:3:1894-9.

124. Ge C, Du J, Zhao L, Wang L, Liu Y, Li D, Yang Y, Zhou R, Zhao Y, Chai Z Chen C. Binding of blood proteins to carbon nanotubes reduces cytotoxicity. Proc Natl Acad Sci USA. 2011;108:16968-73.

125. Long JT, Cheang TY, Zhuo SY, Zeng RF, Dai QS, Li HP, Fang S. Anticancer drug-loaded multifunctional nanoparticles to enhance the chemotherapeutic efficacy in lung cancer metastasis. J Nanobiotechnology. 2014; 12:37.

126. Fishman A, Shalom-Paz E, Fejgin M, Gaber E, Altaras M, Amiel A. Comparing the genetic changes detected in the primary and secondary tumor sites of ovarian cancer using comparative genomic hybridization. Int J Gynecol Cancer. 2005;15:261-6.

127. Noguchi S, Motomura K, Inaji H, Imaoka S, Koyama H. Differentiation of primary and secondary breast cancer with clonal analysis. Surgery. 1994;115:458-62.

128. Nijssen A, Bakker Schut TC, Heule F, Caspers PJ, Hayes DP, Neumann MH, Puppels GJ. Discriminating basal cell carcinoma from its surrounding tissue by Raman spectroscopy. J Invest Dermatol. 2002;119:64-9.

129. Kendall C, Isabelle M, Bazant-Hegemark F, Hutchings J, Orr L, Babrah J, Baker R, Stone N. Vibrational spectroscopy: a clinical tool for cancer diagnostics. Analyst. 2009;134:1029-45.

130. Haka AS, Shafer-Peltier KE, Fitzmaurice M, Crowe J, Dasari RR, Feld MS. Diagnosing breast cancer by using Raman spectroscopy. Proc Natl Acad Sci USA. 2005;102:12371-6.

131. Zhao J, Zeng H, Kalia S, Lui H. Using Raman spectroscopy to detect and diagnose skin cancer in vivo. Dermatol Clin. 2017;35:495-504.

132. Tsikritsis D, Richmond S, Stewart P, Elfick A, Downes A. Label-free identification and characterization of living human primary and secondary tumour cells. Analyst. 2015;140:5162-8.

133. Zhang H, Xiao L, Li Q, Qi X, Zhou A. Microfluidic chip for non-invasive analysis of tumor cells interaction with anti-cancer drug doxorubicin by AFM and Raman spectroscopy. Biomicrofluidics. 2018;12:024119.

134. Staunton JR, Doss BL, Ros RJBJ. Combined Clsm and afm indentation reveals metastatic cancer cells stiffen during Rho/ROCK contractilitydependent invasion of collagen I matrices. Biophys J. 2014;106:176a.

135. Fuhrmann A, Staunton JR, Nandakumar V, Banyai N, Davies PC, Ros R. AFM stiffness nanotomography of normal, metaplastic and dysplastic human esophageal cells. Phys Biol. 2011;8:015007.
136. Capello M, Ferri-Borgogno S, Cappello P, Novelli F. alpha-Enolase: a promising therapeutic and diagnostic tumor target. FEBS J. 2011:278:1064-74.

137. Diaz-Ramos A, Roig-Borrellas A, Garcia-Melero A, Lopez-Alemany R. alpha-Enolase, a multifunctional protein: its role on pathophysiological situations. J Biomed Biotechnol. 2012;2012:1-12.

138. Hsiao KC, Shih NY, Fang HL, Huang TS, Kuo CC, Chu PY, Hung YM, Chou SW, Yang YY, Chang GC, Liu KJ. Surface alpha-enolase promotes extracellular matrix degradation and tumor metastasis and represents a new therapeutic target. PLoS ONE. 2013;8:e69354.

139. Principe M, Ceruti P, Shih NY, Chattaragada MS, Rolla S, Conti L, et al. Targeting of surface alpha-enolase inhibits the invasiveness of pancreatic cancer cells. Oncotarget. 2015:6:11098-113.

140. Song Y, Luo Q, Long H, Hu Z, Que T, Zhang X, et al. Alpha-enolase as a potential cancer prognostic marker promotes cell growth, migration, and invasion in glioma. Mol Cancer. 2014;13:65.

141. Fu QF, Liu Y, Fan Y, Hua SN, Qu HY, Dong SW, et al. Alpha-enolase promotes cell glycolysis, growth, migration, and invasion in non-small cell lung cancer through FAK-mediated PI3 K/AKT pathway. J Hematol Oncol. 2015:8:22.

142. Principe M, Borgoni S, Cascione M, Chattaragada MS, Ferri-Borgogno S, Capello M, et al. Alpha-enolase (ENO1) controls alpha v/beta 3 integrin expression and regulates pancreatic cancer adhesion, invasion, and metastasis. J Hematol Oncol. 2017:10:16.

143. Grubisic G, Klaric P, Jokanovic L, Soljacic Vranes H, Grbavac I, Bolanca I. Diagnostic approach for precancerous and early invasive cancerous lesions of the uterine cervix. Coll Antropol. 2009;33:1431-6.

144. Ikai A. A review on: atomic force microscopy applied to nano-mechanics of the cell. Adv Biochem Eng Biotechnol. 2010;119:47-61.

145. Redondo-Morata L, Giannotti MI, Sanz F. Structural impact of cations on lipid bilayer models: nanomechanical properties by AFM-force spectroscopy. Mol Membr Biol. 2014;31:17-28.

146. Aytac Korkmaz S. Diagnosis of cervical cancer cell taken from scanning electron and atomic force microscope images of the same patients using discrete wavelet entropy energy and Jensen Shannon, Hellinger, Triangle Measure classifier. Spectrochim Acta A Mol Biomol Spectrosc. 2016;160:39-49.

147. Louis DN, Perry A, Reifenberger G, von Deimling A, Figarella-Branger D, Cavenee WK, Ohgaki H, Wiestler OD, Kleihues P, Ellison DW. The 2016 World Health Organization classification of tumors of the central nervous system: a summary. Acta Neuropathol. 2016;131:803-20.

148. Huml M, Silye R, Zauner G, Hutterer S, Schilcher K. Brain tumor classification using AFM in combination with data mining techniques. Biomed Res Int. 2013:2013:176519.

149. Uchihashi T, lino R, Ando T, Noji H. High-speed atomic force microscopy reveals rotary catalysis of rotorless F1-ATPase. Science. 2011;333:755.

150. Adamcik J, Berquand A, Mezzenga RJ. Single-step direct measurement of amyloid fibrils stiffness by peak force quantitative nanomechanical atomic force microscopy. Appl Phys Lett. 2011;98:333.

151. Calzado-Martin A, Encinar M, Tamayo J, Calleja M, San Paulo A. Effect of actin organization on the stiffness of living breast cancer cells revealed by peak-force modulation atomic force microscopy. ACS Nano. 2016:10:3365-74.

152. Alibert C, Goud B, Manneville JB. Are cancer cells really softer than normal cells? Biol Cell. 2017:109:167-89.

153. Heu C, Berquand A, Elie-Caille C, Nicod L. Glyphosate-induced stiffening of $\mathrm{HaCaT}$ keratinocytes, a peak force tapping study on living cells. J Struct Biol. 2012;178:1-7.

154. Uchihashi T, Scheuring S. Applications of high-speed atomic force microscopy to real-time visualization of dynamic biomolecular processes. Biochim Biophys Acta. 2017;1862(2):229-40.

155. Ando T, Uchihashi T, Scheuring S. Filming biomolecular processes by high-speed atomic force microscopy. Chem Rev. 2014;114:3120-88.

156. Sakiyama Y, Mazur A, Kapinos LE, Lim RY. Spatiotemporal dynamics of the nuclear pore complex transport barrier resolved by high-speed atomic force microscopy. Nat Nanotechnol. 2016;11:719-23.

157. Fantner GE, Barbero RJ, Gray DS, Belcher AM. Kinetics of antimicrobial peptide activity measured on individual bacterial cells using highspeed atomic force microscopy. Nat Nanotechnol. 2010;5:280-5. 
158. Efremov YM, Cartagena-Rivera AX, Athamneh AIM, Suter DM, Raman A. Mapping heterogeneity of cellular mechanics by multi-harmonic atomic force microscopy. Nat Protoc. 2018;13:2200-16.

159. Cartagena A, Raman A. Local viscoelastic properties of live cells investigated using dynamic and quasi-static atomic force microscopy methods. Biophys J. 2014;106:1033-43.

160. Watanabe H, Uchihashi T, Kobashi T, Shibata M, Nishiyama J, Yasuda R, Ando T. Wide-area scanner for high-speed atomic force microscopy. Rev Sci Instrum. 2013:84:053702.

161. Vargas-Pinto $R$, Gong $H$, Vahabikashi A, Johnson $M$. The effect of the endothelial cell cortex on atomic force microscopy measurements. Biophys J. 2013;105:300-9.

162. Lekka M. Discrimination between normal and cancerous cells using AFM. Bionanoscience. 2016:6:65-80.

163. Radmacher M. Studying the mechanics of cellular processes by atomic force microscopy. Methods Cell Biol. 2007:83:347-72.

164. Gavara N. Combined strategies for optimal detection of the contact point in AFM force-indentation curves obtained on thin samples and adherent cells. Sci Rep. 2016;6:21267.

165. Plodinec M, Loparic M, Monnier CA, Obermann EC, Zanetti-Dallenbach R, Oertle P, Hyotyla JT, Aebi U, Bentires-Alj M, Lim RY, Schoenenberger CA. The nanomechanical signature of breast cancer. Nat Nanotechnol. 2012;7:757-65.

166. Lekka M, Gil D, Pogoda K, Dulinska-Litewka J, Jach R, Gostek J, et al. Cancer cell detection in tissue sections using AFM. Arch Biochem Biophys. 2012;518:151-6.
167. Junttila MR, de Sauvage FJ. Influence of tumour micro-environment heterogeneity on therapeutic response. Nature. 2013;501:346-54

168. Quail DF, Joyce JA. Microenvironmental regulation of tumor progression and metastasis. Nat Med. 2013;19:1423-37.

169. Burrell RA, McGranahan N, Bartek J, Swanton C. The causes and consequences of genetic heterogeneity in cancer evolution. Nature. 2013:501:338-45.

170. Cartagena-Rivera AX, Wang WH, Geahlen RL, Raman A. Fast, multi-frequency, and quantitative nanomechanical mapping of live cells using the atomic force microscope. Sci Rep. 2015;5:11692.

171. Dufrene YF, Ando T, Garcia R, Alsteens D, Martinez-Martin D, Engel A, Gerber C, Muller DJ. Imaging modes of atomic force microscopy for application in molecular and cell biology. Nat Nanotechnol. 2017:12:295-307.

172. Guan D, Charlaix E, Qi RZ, Tong PJ. Noncontact viscoelastic imaging of living cells using a long-needle atomic force microscope with dual-frequency modulation. Phys Rev Appl. 2017:8:044010(044011)-044010(044010).

173. Churnside AB, Perkins TT. Ultrastable atomic force microscopy: improved force and positional stability. FEBS Lett. 2014:588:3621-30.

174. King GM, Carter AR, Churnside AB, Eberle LS, Perkins TT. Ultrastable atomic force microscopy: atomic-scale stability and registration in ambient conditions. Nano Lett. 2009:9:1451-6.
Ready to submit your research? Choose BMC and benefit from:

- fast, convenient online submission

- thorough peer review by experienced researchers in your field

- rapid publication on acceptance

- support for research data, including large and complex data types

- gold Open Access which fosters wider collaboration and increased citations

- maximum visibility for your research: over 100M website views per year

At BMC, research is always in progress.

Learn more biomedcentral.com/submissions 